\title{
Types and Causes of Students’ Disruptive Behavior in Classroom at Secondary Level in Khyber Pakhtunkhwa, Pakistan
}

\author{
Safdar Rehman Ghazi*, Gulap Shahzada, Muhammad Tariq, Abdul Qayum Khan \\ Institute of Education and Research, University of Science and Technology, Bannu, Khyber Pakhtunkhwa, Pakistan \\ *Corresponding author: drsrghazi@yahoo.com
}

Received August 03, 2013; Revised September 26, 2013; Accepted October 06, 2013

\begin{abstract}
Secondary school teachers have repeatedly ranked disruptive behaviour as one of the most serious hurdle in effective teaching learning process in the classroom. It has also been reported that the students in public schools feel insecure due to lack of effective disciplinary measures and probable for aggression and unpleasant situation. Teachers are often not well prepared to manage classrooms' discipline. The present study aimed to investigate the types and causes of disruptive behaviour in classroom at secondary level. Teachers who were teaching in the secondary schools of Khyber Pakhtunkhwa constituted the population of the study. Five hundred (500) teachers were taken as sample, using multi-stage random sampling method. A questionnaire was developed on five point Likert Scale and was distributed among the sampled teachers and collected their responses regarding the types and causes of students' disruptive behaviour in classroom. Some of the types of disruptive behaviour were reported unanimously reported by most of the teacher however a significant deviation has been reported. It is recommended that the disruptive behaviour of students of secondary schools in Pakistan needs an extensive attention of educators, policy makers and the government to address this area for quality education in the country. For this purpose proper trainings may be arranged for administrators and teachers to equip them regarding disruptive behavior and classroom management.
\end{abstract}

Keywords: classroom management, disruptive behaviour, secondary school

Cite This Article: Safdar Rehman Ghazi, Gulap Shahzada, Muhammad Tariq, and Abdul Qayum Khan, “Types and Causes of Students' Disruptive Behavior in Classroom at Secondary Level in Khyber Pakhtunkhwa, Pakistan.” American Journal of Educational Research 1, no. 9 (2013): 350-354. doi: 10.12691/education-1-9-1.

\section{Introduction}

Disruptive behavior in the secondary schools in Pakistan, particularly in Khyber Pakhtunkhwa has become a great problem. Teachers have complaints against behavioural problems relating to students in classroom management. The classrooms where disruptive behavior occurs frequently gets less academic engaged time, and the students in disruptive classrooms stand in low category in achievement tests. Furthermore, attempts to control disruptive behaviors cost considerable teachers' time at the expense of academic instructions in the class. School discipline issues such as disruptive behavior and violence also have an increased effect on teacher stress and burnout. [1] There is a major body of research supporting the fact that classroom organization and behavior management competencies considerably affect the perseverance of new teachers in their teaching careers. [2] New teachers require effective means to handle disruptive behavior. [3] Teachers who have significant problems with behavior management and classroom discipline often report high levels of disappointment and stress and are simultaneously ineffective. [4] Sometimes it becomes extremely difficult to organize classrooms and deal with the disruptive behavior simultaneously, which is indispensible for the academic outcomes.

Disruptive is not merely a naughty behaviour of student but it goes beyond the normal the routine disturbance in the classroom. Sometimes a single child disturbs the whole classroom so much that neither the child who creates disruption nor the other children sitting beside him/her can learn. Disruptive behaviour directly put teachers, children and parents in embarrassing situations. Therefore it has become a matter of great concern for the educators. They put their heads down and think an effective treatment that how a teacher may cope with such behaviour and how the child and the other children can be protected. As reference [5] shows that disruptive behaviour is simply the behaviour which doesn't allow the teachers and students for teaching learning process. According to reference [6], the learners have their fundamental right to have a safe and respectful environment for learning, so the disruptive behaviour is a disciplinary problem and must be dealt technically.

There is a dire need to distinguish between disruptive behaviour of a student in classroom (which directly exerts negative impacts on the efforts of the instructor to teach or the ability of other students to learn the topic in the 
classroom) and the behavior that is merely inappropriate. The latter may become disruptive when it persists for long time. Student's disruptive behavior is disadvantageous to the educational society because it interferes with the learning process for other students, retards the ability of teachers to teach most effectively, diverts the energy and resources of teachers and school away from their objectives and educational mission, and may designate a significant height of personal problems or anguish on the part of the disrupter.

Most of the heads of institutions set up some sorts of rules and measures at the commencement of the academic year. They also try to be abiding in implementing those rules and measures. It will be expected that positive results would be achieved, whenever the rules are implemented, and whereas if the rules are breached may create harmful repercussion. Keeping under consideration the present scenario, some newer standpoints on classroom management have been set up with the help of this study that try to be holistic. These newer perspectives are quite helpful and we expect that it will guide our students towards a successful behavior which will be more fruitful in the classroom. It is hoped that students will smoothly perform their role and consequently will achieve their goals.

Beside disruptive behaviour, the term class room management is equally important to be taken under consideration. Prominent educators have time and again ranked classroom discipline as one of the most serious hurdle in the way of educational objectives. Moreover, it has been observed to be the most widespread cause of job fatigue, disappointment and abrasion for new teachers. It is one of the reasons that teachers have got their apprehension over their own safety which is directly related to classroom management strategies. It has also been reported that the students in public schools feel insecure because of lack of effective measures and probable for aggression and unpleasant situation which may be created due to disruptive behaviour.

\subsection{Background of the Study}

This is universally acknowledging fact that we are neither wholly free to behave as we choose for ourselves, nor our behaviour is wholly determined by the social norms. [7] Therefore some customary rules and regulation are required for smooth performance and peaceful life. There have been some traditional treatments in schools keeping the students disciplined, which are now outdated and inapplicable.

Since banning of corporal punishment in schools vide bill number 131 by the National Assembly of Pakistan, many educators claim that problem behaviour has been increased intensively and occur more frequently in classrooms, the use of corporal punishment was part of authoritarian approach to managing classroom environment. A common sentence was used "spare the rod spoil the child". This sentence was very famous among the old teachers and heads of schools particularly for dealing with the disruptive behaviour of students of secondary level. Children enter in the secondary school at the start of teen age, which is a juvenile age, at this stage the children urge for grandstanding in the classroom, street, playground, friends and family, during this age any kind of psychological or biological deficiency appears more vigorously and compel the student to behave obtrusively. Attention Deficit Disorder (ADD) and Attention Deficit and Hyperactivity Disorder (ADHD) among the students of teenage were also thought to be the core causes of disruptive behaviour, the researcher was interested to dugout the different types and causes of this abnormal behaviour of students of the target schools. The need was felt to give emphasis to students' disruptive behaviour in the research so that some important areas related to its impacts on classroom management may be highlighted through it. So the purpose of this study was to explore types and causes of students' disruptive behavior in classrooms of secondary schools in Khyber Pakhtunkhwa, Pakistan.

\subsection{Statement of the Problem}

There are different kinds of disruptive behaviour and each one has different causes which has negative impact on classroom management. The present study aims to explore "Types and Causes Students' Disruptive Behavior in Classroom at Secondary Level”.

\subsection{Objectives of the Study}

Since banning of corporal punishment in schools the teachers were found in great trouble because even the students became aware of the law against corporal punishment and they claim that they cannot be given corporal punishment at any cost, which in turn, escalated the intensity as well as the frequency of disruptive behavior. In such situation there is a dire need of some laws and techniques for minimizing the disruptive behavior and its impact on classroom management. The tried beckon the attention of the policy makers and politicians towards such a serious problem. Therefore the following objectives were set for the study:

1. To discover the different types of students' disruptive behaviour as viewed by the teachers of secondary schools in Khyber Pakhtunkhwa, Pakistan.

2. To find out causes of disruptive behaviour in classroom perceived by the teacher in secondary schools in Khyber Pakhtunkhwa, Pakistan.

3. To give some recommendations for students' disruptive behaviour in classroom.

\section{Research Methodology}

The purpose of the study was to investigate the types and causes of student's disruptive behaviour in classroom in secondary level as perceived by the teachers of secondary schools. Therefore the research study was descriptive/ survey type.

All the secondary schools teachers of Twenty Five (25) districts of Khyber Pakhtunkhwa constituted population of the study and the sample of Eight (8) districts was selected through multistage random sampling. A sample of five hundred (500) secondary schools teachers were selected from 213 sampled schools. Total 437 (87\%) questionnaires were received back.

A self-developed questionnaire on five point Likert scale [Strongly Agree (SA), Agree (A), Undecided (UD), Disagree (DA) and Strongly Disagree (SDA)] was employed to explore the perceived observations of 
secondary school teachers regarding types and causes of student's disruptive behaviour in classroom.

Reliability of the instrument was checked with the help of split half reliability and coefficient alpha, a small data of fifty respondents were taken, the researcher randomly split the test into two then calculated respondents' scores on each 'half test', two scores were related to one another, they both were measuring the same thing, they were strongly related with a correlation coefficient 0.86 .

The respondents were personally approached in their schools by one of the researchers. They were asked to fill the questionnaires and also informed about the purpose of research, about the questionnaire, and how it will be filled out. Along with that the instructions were also available on the questionnaire. Relevant data was collected through the questionnaire. SPSS 16 was used for recording, tabulation and analysis of data.

\section{Findings}

The collected data was entered in SPSS16 and Chisquare test of goodness of fit was used as statistical tool.

Table 1. Observed Frequencies on different Types of Disruptive Behavior

\begin{tabular}{|c|c|c|c|c|c|c|}
\hline Type of Behavior & SDA & DA & UD & A & SA & $\chi^{2}$ \\
\hline Trying to gain influence among his/her fellows & 34 & 71 & 108 & 205 & 19 & 252.3 \\
\hline To gain power in classroom threaten teacher & 17 & 53 & 121 & 218 & 28 & 318.6 \\
\hline Entering in the classroom with screaming sounds & 34 & 83 & 110 & 183 & 27 & 185.0 \\
\hline Sleeping during teaching & 36 & 57 & 97 & 193 & 54 & 182.2 \\
\hline Chatting with one another during teaching & 5 & 53 & 99 & 217 & 63 & 291.7 \\
\hline Coming to classroom habitually late & 18 & 50 & 88 & 202 & 79 & 222.1 \\
\hline Unnecessarily arguing with teachers & 4 & 187 & 79 & 123 & 44 & 229.9 \\
\hline Bringing noisy electric devices in the classroom & 13 & 37 & 120 & 226 & 41 & 348.9 \\
\hline Blaming one another upon any mischief & 0 & 13 & 79 & 240 & 105 & 249.8 \\
\hline Initiating quarrel among the students & 44 & 46 & 99 & 197 & 51 & 195.2 \\
\hline Shouting loudly to create thrill in classroom & 15 & 115 & 96 & 181 & 30 & 207.4 \\
\hline Wandering in Veranda to diverge students' attention & 13 & 34 & 125 & 214 & 51 & 310.6 \\
\hline Start answering before the question finishes & 2 & 26 & 113 & 227 & 69 & 360.9 \\
\hline Playing with (hands, feet, Pen etc) & 12 & 128 & 87 & 188 & 22 & 248.6 \\
\hline Using rough language with other students and teacher & 17 & 83 & 109 & 189 & 39 & 207.1 \\
\hline Reporting others for his or her mistakes or misbehavior & 1 & 109 & 125 & 160 & 42 & 190.8 \\
\hline Deliberately destroying things/materials & 0 & 89 & 110 & 159 & 79 & 34.7 \\
\hline Challenging the teacher on certain concepts & 5 & 132 & 99 & 154 & 47 & 171.4 \\
\hline Discussing religious/ sectorial issues & 0 & 160 & 110 & 121 & 46 & 61.4 \\
\hline Ignoring the teacher's directions & 0 & 50 & 93 & 219 & 75 & 155.5 \\
\hline Shifting from one Chair to another & 6 & 60 & 110 & 185 & 76 & 200.7 \\
\hline Losing temper on slight penalty given by teacher & 12 & 52 & 117 & 212 & 44 & 288.5 \\
\hline Making complaints against his/her fellows & 10 & 135 & 91 & 163 & 38 & 187.9 \\
\hline
\end{tabular}

Expected Frequency $=87.4$

In Table 1 chi square values show a significant difference between the observed frequencies and expected frequency for all the types of selected disruptive behavior at 0.05 level of significance. Interestingly, all the observed frequencies show that the types of selected disruptive behaviour of the students are very important and the selected problem is of immense value. In short, all the following types of students' disruptive behavior were reported significant by the respondents.

1. Trying to gain influence among his/her fellows

2. Trying to gain power in classroom to threaten teacher

3. Entering in the classroom hurriedly with screaming sounds

4. Sleeping during teaching

5. Chatting with one another during teaching

6. Coming to classroom habitually late

7. Unnecessarily arguing with teachers

8. Bringing noisy electric devices in the classroom

9. Blaming one another upon any mischief

10. Initiating quarrel among the students

11. Shouting loudly to create thrill in classroom

12. Wandering in Veranda which diverge attention of students inside the classrooms
13. Start answering before the question finishes

14. Playing with (hands, feet, Pen etc)

15. Using rough language with other students and teacher

16. Reporting others for his or her mistakes or misbehavior

17. Deliberately destroying things/materials

18. Challenging the teacher on certain concepts

19. Ignoring the teacher's directions.

20. Shifting from one Chair to another.

21. Discussing religious/sectarian issues.

22. Losing temper on slight penalty given by teacher.

23. Making complaints against his/her fellows.

In Table 2 chi square values show a significant difference between the observed frequencies and expected frequency for all the selected causes of disruptive behavior at 0.05 level of significance. It is noteworthy that all the observed frequencies show that the respondents are in the support of the selected causes of classroom disruptive behaviour of the students. Although the intensity of each cause is almost different from the other cause, however, all the causes are found with a high chi square value. It can also be inferred that the favor of the teachers for all 
the causes with a high value also shows the importance of the problem in hand. In short, all the following causes of the students' disruptive behavior were reported significant by the respondents.

1. Inconsistent parenting.

2. Uncaring parents.

3. Over-protective parents.

4. Bad influences on a student's local community.

5. Poverty.
6. Poor quality teaching.

7. Teachers' negative attitude towards student.

8. Repeating change in subject teacher.

9. Repeating the same class.

10. Lack of motivation from teacher.

11. Repeating the same class.

12. Classroom poor conditions (lack of Lighting, ventilation, sounds etc.)

13. Some psychological problems of a student.

\begin{tabular}{|c|c|c|c|c|c|c|}
\hline Causes & SDA & DA & UD & A & SA & $\chi^{2}$ \\
\hline Inconsistent parenting & 0 & 54 & 90 & 208 & 85 & 125 \\
\hline Uncaring parents & 0 & 81 & 133 & 162 & 61 & 59.2 \\
\hline Over-protective parents & 10 & 165 & 93 & 136 & 33 & 198.6 \\
\hline Bad influences of a local community & 5 & 157 & 91 & 132 & 52 & 170.3 \\
\hline Poverty & 9 & 93 & 100 & 174 & 61 & 166.2 \\
\hline Poor quality teaching & 0 & 183 & 110 & 109 & 35 & 100.2 \\
\hline Teachers' negative attitude & 0 & 179 & 106 & 112 & 40 & 88.5 \\
\hline Repeating change in subject teacher & 0 & 208 & 91 & 94 & 44 & 133.4 \\
\hline Repeating the same class & 2 & 170 & 104 & 116 & 45 & 194.5 \\
\hline Lack of motivation from teacher & 1 & 105 & 87 & 186 & 58 & 210 \\
\hline Load shedding and lack of alternative & 0 & 216 & 89 & 93 & 39 & 155.6 \\
\hline Classroom poor conditions & 1 & 148 & 84 & 148 & 56 & 180.8 \\
\hline Students’ psych-problems & 0 & 108 & 107 & 163 & 59 & 49.6 \\
\hline
\end{tabular}

Expected Frequency $=87.4$

\section{Discussion}

It is evident from the research of different researchers that disruptive behaviour always has created unrest among the peers, colleagues and classmates of different ages but this study particularly focused in the context of classroom management of secondary level where the students pass through teenage. The more specified nature of the study helped in getting projected results and paved the ways for achievement of objectives of the study. Disruptive behavior in the Secondary schools of Khyber Pakhtunkhwa has become a big dilemma whose proper solution has become indispensable for teachers and administrators for the last several years particularly since the banning of corporal punishment. Indeed, the issue has become a talk of the town among the teachers of secondary schools and is directly related to behavior and classroom management. Disruptive behaviour of a student not harm him/her bit disturb the whole class, in severe cases it jeopardize the whole system. Disruptive behaviour concerns teachers, children and parents.

During collection of data, the researcher found that most of the teachers took remarkable interest in solving the questionnaire and reporting the types and causes of disruptive behavior which strengthen the intent of the researcher.

\section{Conclusions}

The researcher found from the research that the student's disruptive behaviour is a big challenge in teaching-learning process in classrooms of secondary schools of Khyber Pakhtunkhwa, the teachers have unanimously reported the presence of almost all kinds of student's disruptive behaviour irrespective of the differences in the nature, operation and background of the schools. The causes of students' disruptive behavior reported by the teachers are almost the same as evident from the researchers of different social background. Most of the types and causes reported in this study are easily quantifiable to be controlled.

\section{Recommendations}

The following recommendations are made:

1. Teaching strategies may be revised in the context of student's disruptive behaviour in order avoid it and minimize the impacts of disruptive behaviour.

2. Some scholarly persons may be detailed to visit the secondary schools and deliver lectures periodically, keeping disruptive behaviour under consideration.

3. Seminars for parents, teachers and students may be arranged on the topic of disruptive behaviour to highlight the impacts, remedies and repercussions of student's disruptive behaviour.

4. Some standing operating procedures may be introduced as remedy to disruptive behaviour on provincial level.

5. A ranking system may be introduced for behavior as marking bad, good, better and excellent behaviour for students, which may escalate or deescalate admissions and scholarships in order to reduce the student's disruptive behaviour.

6. The heads of schools may set some sorts of rules and regulations for disruptive behaviour, which may help the teachers as rigid supports and guide lines. 
7. Teaching methods may be made more motivational in order to attract students towards studies, the more they get involved in studies the more they behave appropriately.

\section{References}

[1] Smith, D. L., \& Smith, B. J. (2006). Perceptions of violence: The views of teachers who left urban schools. The High School Journal, 89, 34-42.

[2] Ingersoll, R. M., \& Smith, T. M. (2003). The wrong solution to the teacher shortage. Educational Leadership, 60, 30-33.
[3] Browers A., \& Tomic, W. (2000). A longitudinal study of teacher burnout and perceived self-efficacy in classroom management. Teaching and Teacher Education, 16, 239-253.

[4] Berliner D.C. (1986) In pursuit of expert pedagogue, Educational research 15(7), 5-13.

[5] Gordon AM \& Browne KW 2004. Beginnings and beyond: Foundations in Early Childhood Education, 6th edn. Australia: Delmar Learning.

[6] Mabeba MZ \& Prinsloo E 2000. Perceptions of discipline and ensuing discipline problems in secondary education. South African Journal of Education, 20:34-41.

[7] Cooper, P. \& Upton, G. (1990) An Ecosystemic Approach to Emotional and Behavioural Difficulties in Schools. Educational Psychology, Vol. 10, No. 4, 301-321. 